\title{
E-mail-based Exercises in Happiness, Physical Activity and Readings: A Randomized Trial on 3274 Finns
}

Kaisla Joutsenniemi ${ }^{*}$, Carl Kaattari ${ }^{1}$, Tommi Härkänen $^{2}$, Maiju Pankakoski ${ }^{2}$, Heimo Langinvainio ${ }^{3}$, Jouko Lönnqvist ${ }^{2}$, Antti S Mattila $^{4}$, Pekka Mustonen $^{5}$

${ }^{1}$ University of Helsinki, Helsinki, Finland

${ }^{2}$ National Institute for Health and Welfare, Department of Health, Functional Capacity and Welfare, , Helsinki, Finland

${ }^{3}$ Competence Audit Center, Espoo, Finland

${ }^{4}$ Psychotherapist, Antifon, Eteläinen Hesperiankatu 22, Fl-00100 Helsinki, Finland

*Corresponding author: Kaisla Joutsenniemi, National Institute for Health and Welfare, Mental Health Problems and Substance Abuse Services Unit, PO Box 30 , FI-00271 Helsinki, Finland, Tel: +358503300 142; E-mail: kaisla.joutsenniemi@icloud.com

Received date: April 2, 2014, Accepted date: September 1, 2014, published date: September 10, 2014

Copyright: (c) 2014 Kaisla Joutsenniemi et al., This is an open-access article distributed under the terms of the Creative Commons Attribution License, which permits unrestricted use, distribution, and reproduction in any medium, provided the original author and source are credited.

\begin{abstract}
Objective: Rigorous research in the last decade has demonstrated the efficacy of specific techniques in positive psychology that enhance psychological well-being. Online positive psychology interventions have the potential to enhance positive well-being in large audiences, including hard-to-reach target groups. There is lack of data on the effect of positive psychology exercises on happiness and on depressive symptoms in comparison with physical activity exercises and a placebo group.
\end{abstract}

Methods: The Finnish Happiness-Flourishing Study (FHFS) included a TV-program on happiness interventions, a happiness website and an email-based happiness exercise intervention. A three-armed randomized controlled trial was conducted on 3274 Finnish adults in 2011. The participants were assigned to receive happiness exercises, tailored physical activity exercises or reading exercises on happiness (i.e. placebo). The statistical analyses were based on the intention-to-treat principle and linear random effects models.

Results: The overall happiness scores increased $\left(X^{2}=7.83, d f=3, p=0.05\right)$ and depressive symptoms decreased $\left(X^{2}=5.5, d f=1, p=0.02\right)$ during the intervention, with more pronounced changes among women. The order of the four different happiness exercises did not have a systematic effect on the happiness score. The exercise on good deeds had the strongest effect on the improvement of the happiness score (change $=4.50,95 \% \mathrm{Cl}=2.47-6.52$ ) whereas for the optimism exercise there was no improvement (change $=0.46,95 \% \mathrm{Cl}=-1.55-2.48$ ). In the physical exercise group, there was an increase in the proportion of physically active subjects as compared with the placebo reading-group $\left(X^{2}=8.4, d f=1, p=0.004\right)$.

Conclusions: This study produced further evidence on the effectiveness of web-based happiness exercises. The results amplify the need for tailored online interventions for reducing well-being disparities. Further studies also need to increase the current understanding of the relative importance of variety in the application of positive interventions. Online positive psychology interventions are a potential tool in helping reduce well-being disparities, particularly among populations with little access to other services.

Keywords: Web-based; Online; Randomized study; Intervention; Happiness; Physical exercise; Depressive symptoms

\section{Introduction}

Positive psychology is the scientific study of psychological wellbeing and optimal functioning, which provides a perspective to mental health beyond the absence of psychiatric symptoms [1]. Rigorous research in the last decade has demonstrated the efficacy of specific techniques that enhance psychological well-being [2,3]. In particular, internet-based interventions have proved to be a valuable tool in spreading information and exercises based on positive psychology.

In a national sample from the US, two thirds of internet users have been estimated to search for health information in 2005 [4]. Individuals seeking for enhanced well-being or happiness, who would be unable or unwilling to receive face-to-face counseling, might have motivation and access to online intervention options, thus, online interventions have the potential to promote mental well-being on a broad scale. Other advantages of online interventions include their cost- and time-effectiveness [5]. In a previous study on 912 self-help seeking adults in the United States, the subjects arrived at the study website either by web-browsing or via a well-known positive psychology website. The participants reported depressive symptoms above the mean of the general population and life satisfaction below the average [6]. There is great potential in offering web-based interventions to happiness seekers with mild symptoms of mental disorders, as depressive symptoms may be decreased [3] and the development of more serious mental health disorders may be prevented $[7,8]$. TV-programs and movies based on happiness may also attract individuals with needs to increase their own well-being. As a recent review [9] points out, the potentially advantageous 
combination of different media, such as television, radio and internetbased techniques, has remained underused.

Web-based interventions using cognitive behavioral therapy (CBT) [10] and behavioural [11] techniques are well-known to alleviate depressive symptoms, and recent research has shown web-based CBT to promote positive mental health [12]. Regarding web-based positive psychology interventions, several randomized controlled studies (RCT) have shown that they also have the potential to enhance positive well-being and to alleviate symptoms of depression. So far, these RCT:s have had relatively small samples with up to 10 -week interventions. One of the first happiness-interventions included 577 adults recruited from a positive psychology website based in the United States [2]. Three out of five happiness exercises decreased depression and increased happiness after the 1-week post-intervention assessment, namely the gratitude visit, three good things in life, and using signature strengths in a new way. The latter two last exercises increased happiness and decreased depressiveness for six months [2]. Since this classic study, several studies have repeated these results comparing happiness exercises with placebo controls $[13,14]$. There is little previous information on the relevance of the order of happiness exercises and efficacy of separate happiness exercises. Furthermore, although physical exercise has also been shown to alleviate symptoms of depression [15] and to moderately increase overall wellbeing (physical, mental, and job wellbeing)[16], few studies have assessed the effects of physical exercise on happiness [17]. Online physical exercise interventions have reported promising results on increasing physical activity, [18], but the effects on online physical activity interventions on depressive symptoms or happiness have remained understudied.

The Finnish Happiness-Flourishing Study (FHFS) included a TVprogram on happiness interventions, a happiness website and an email-based happiness exercise intervention delivered to a sample of 3274 Finnish adults. The aim of this study was to examine the efficacy of email-based happiness exercises in comparison to email-based physical activity exercises, and a placebo control (email-based reading exercises). Regarding primary outcomes, it was hypothesized that: 1) the happiness exercise group would demonstrate an increase in happiness and decrease in depressive symptoms at post-assessment; 2) the physical exercise group would demonstrate a decrease in depressive symptoms at post-assessment; and 3) there would be no changes in happiness or depressive symptoms in the placebo group. Regarding secondary outcomes, it was hypothesized that; 4) the order of happiness exercises would not affect the level of change in happiness scores; 5) there would be no efficacy differences between the different happiness exercises in increasing happiness scores; and 6) the level of physical activity would increase in the groups receiving physical exercises.

\section{Data and Methods}

\section{Data}

The Finnish Happiness-Flourishing Study (FHFS) is a national collaboration with Duodecim Medical Publishing Ltd., the National Institute for Health and Welfare, Tarinatalo [a Finnish television production company], and Finland's national public service broadcasting company YLE. The study website offering access to the happiness test was freely available and a part of the national publicly funded Finnish Broadcasting Company's (YLE TV1) large website that offers e.g. a national news service, tv-program information, national weather information, regional news and a national, educational section for the primary schools, as well as archives of published TV-programs. The happiness website gave detailed information of the TV-program, the five main characters, some information on the happiness-test and its development by the Finnish Medical Society Duodecim and the National Institute of Health and Welfare in Finland, as well as the link to the actual test.

At the happiness website, 139462 Finns measured their own happiness on the Happiness-Flourishing Scale (HFS) and identified their important sources of happiness. They also answered questionnaires including background variables (described below). The baseline results from this study have been described in detail [19]. After entering their own answers to the HFS, the participants received information on how their results compared to other Finns. After excluding subjects who were not within the age range 18-99 $(n=38205)$, about $10.4 \%(N=10485)$ of the sample had given approval for re-contacting.

\section{Procedure}

On 21.1.2011 (and a reminder email on 26.1.2011) we recontacted the 10,485 subjects by email and described our forthcoming emailbased intervention as an opportunity to get involved in happiness training. As an encouragement to participate, the subjects were informed about a lottery for 10 Happiness skills -books and one trip to Athens for two persons (i.e. a voucher for a travel agency). The email stated that the intervention would include three different types of happiness-enhancing exercises, but they were not informed about which group they would be randomized into. The happiness intervention was conducted between 31.1.-13.6.2011 for 3274 participants, and the post-intervention questionnaire was sent in 20.6.2011 (reminder on 5.7.2011). The study also included a 12-month follow-up period (data not shown).

The intervention study was approved by the ethics committee for Ethics Committee for Gynecology and Obstetrics, Pediatrics and Psychiatry in the Hospital District of Helsinki and Uusimaa, Finland.

\section{Intervention}

In this three-armed randomized controlled trial, participants were assigned to the Happiness group $(n=1038)$, to the physical exercise group $(n=1181)$ or to the placebo-control (reading exercise) group $(n=1055)$ using the random allocation with ratio 1:1:1. The random allocation sequence was generated using computer software, and the sequence was merged with the list of email addresses. All participants received instructions by email. Altogether the intervention lasted for 4 months.

All participants received short texts to read, which we selected from the Finnish book "Happiness skills" [20]. The 26 different texts could be considered as general information about happiness and did not comprehend any happiness exercises.

The participants in the happiness group also received sequentially four different happiness exercises: good deeds, gratitude, optimism and reducing rumination. Each exercise consisted of seven messages containing instructions and each message was delivered approximately every four-five days, i.e. 3 messages per two weeks. The different groups of exercises were delivered in random order. The exercises were placed before the short texts in the emails. Because it was not known if different orderings of the exercises had different effect on the outcomes, this intervention group was further randomized into 24 
groups defined by all possible permutations of the four exercises. This allowed us to test possible nonequivalence of the permutations. The good deeds exercise was based on the "random acts of kindness"exercise [21]. The participants were encouraged to do 3-5 small good deeds within one day during the next five days. Each new message reminded the participant of doing the good deeds during the next fiveday-period, and the messages also described in one sentence what kind of positive effects this exercise could induce. The gratitude exercise $[22,23]$ encouraged participants to choose one night during the next five days for doing the following exercise" : In our lives there are a lot of things, small and big, that we could be grateful for. Think about the events of the past few days and write down in your diary five things you are grateful for." The next six gratitude messages reminded of the original exercise and described in one sentence what kind of positive effects this exercise could induce. The optimism exercise was based on writing about life goals [24]. Take paper and a pen and reserve 15 minutes for this exercise. Imagine what your life is like in five years, when you have reached all your goals. Write about this for 15 minutes as vividly, concretely and in detail as possible. Continue writing this description for 15 minutes every day for the next four weeks. The next five messages reminded of the writing exercise and briefly referred to ancient philosophers' thoughts on optimism. The seventh message encourages to question and doubt pessimistic thoughts as a tool for strengthening optimism [22]. The message specifically advises as follows" : The following questions may assist in restructuring a situation: What else could this situation or experience mean? Could something good come out of this? Does this offer me new possibilities? What could I learn and apply in the future? Did this unravel or develop some strength in me? The first message on reducing rumination $[22,25]$ described the harmful effects of excess rumination. The second message advised to focus one's attention to other activities (with examples) than rumination. The third message described how to reserve 30 minutes for daily rumination instead of constant rumination. The fourth message encouraged to make a list of situations that activate rumination, so that one could avoid these situations. The fifth message advised on how to bring one's attention back to the present moment, if rumination bothers you during the night": In your mind, list five things that you see, list five things that you hear, and list five things that you can feel touching your body. Next, list 4-3-2-1 item in each category". The sixth message instructed how to bring oneself back to the present moment by focusing on one's breathing. The final, seventh message gave advise on learning to relax oneself by progressively tensing and relaxing each area of one's body.

The reading exercise group (=placebo group) received only the short texts, with an interval of four-five days (in order to send 3 messages per two weeks). On the basis of their previous physical activity and health status assessed by The Physical Activity Readiness Questionnaire (PAR-Q)[26], the physical exercise group was divided into five subgroups. Subjects with various health conditions only received the short texts (0-group, $n=201$ ) and were thus moved to the placebo group to receive only the reading exercises. The other four groups: group $1(\mathrm{n}=244)$, group $2(\mathrm{n}=318)$, group $3(\mathrm{n}=403)$ and group $4(n=15)$ received instructions on physical exercises customized according to their fitness levels, i.e. light exercise for group 1 with no previous exercise habits, and intense exercise for group 4 with reported regular competitive exercise. The exercise program included three training periods, which lasted for 6 weeks each. At the beginning of each period, the participants received their forthcoming exercise program. In addition, each group received once a week a supportive email,which included alternative forms of physical activity and tips for muscle maintenance and the importance of rest. In order to be suitable for as many as possible, individuals were given a number of of exercise options, i.e. running, walking, swimming, cycling, ball games and skiing. The amount of exercise per week and the intensity of each exercise were dependent on the previous exercise background (group 1 light exercise, group 4 heavy exercise). The participants in exercise group 1 were encouraged to exercise 3-4 times per week with moderate intensity. The suggested exercises were walking, Nordic walking, skiing, team sports, swimming, cycling and gardening. Each training session was recommended to last from 30 minutes to 1 hour.

The participants in exercise group 4 were suggested to exercise 6-7 times per week with high intensity. Especially running, swimming,cycling, skiing, gym training and ball games were recommended. Each training session was designed to last from 45 minutes to 2 hours depending on the intensity-level. The amount of exercise and training-intensity in group 2 and 3 varied between group 1 and 4 exercise programs.

The repeated measurements for all variables were assessed at baseline and at the end of the 4-month intervention. In addition, during the intervention each participant received two mini-inquiries at the change points (i.e. every 7 weeks) of the happiness exercises. The mini-inquiries included questionnaires on three dimensions of wellbeing; (happiness scores (Happiness-Flourishing Scale (HFS) described under "Variables"), happiness skills (data not shown) and life satisfaction (data not shown). The measure and time point was randomized individually. No interim analyses were performed.

\section{Outcome variables}

In order to define the efficacy of the happiness, physical activity and reading exercises, our primary outcome measure was happiness, and the secondary outcomes were depressive symptoms and physical activity.

A new Happiness-Flourishing Scale [HFS] was developed as a part of the Finnish Happiness Flourishing Study. The HFS consists of 10 items [1-7 scale] including experienced general happiness, moments of happiness, actualization of competences, optimism, meaningfulness of life, a life worthwhile, being in charge of one's life, comparative happiness, contribution to other people's lives and inner peace. After each item, subjects were to choose an answer that best reflected their answer on a 7-point Likert scale.

Depressive symptoms were measured by the 21 -item modification [27] of the Beck Depression Inventory (BDI), which has been shown to have good psychometric properties [28-30]. BDI sum scores were categorized as follows: none or minimal depressive symptoms 0-9, mild depressive symptoms 10-18, and moderate to severe depressive symptoms [19-63].

As the exercises focused on leisure time physical activity, leisure time physical activity was recorded by asking the following questions: "How much do you exercise and strain yourself physically in your leisure time?" (the so-called Gothenburg scale)[31].

\section{Background variables}

The level of education was captured with an open-ended question" How many years have you attended school or studied full time?" and participants responded as full years. Education was included in the analyses as a continuous variable. Answering options on current main activity included full-time employment; part-time employment; 
student; retired; unemployed or laid off; management of own household or care of family members; conscript or non-military service; other? Employed subjects were asked about their work capacity as follows" : Do you think that, as far as your health is concerned, you could continue in your present occupation after two years? Followed by the options 1) probably not; 2) I am not sure; 3) probably yes. The answering options for living arrangements included alone; with spouse; with spouse and children; with children (single parent/joint custody); with parent(s); other. Relationships satisfaction was assessed by the item "My relationship with my spouse/partner is..." followed by 7 options ranging from very good to very poor.

Smoking was assessed by the question "How many cigarettes, cigars or pipefuls do you smoke per day? Smoking at least once a day was dichotomized as regular smoking. An open text field followed the question "How many units of alcohol do you drink per week?" At least 7 weekly doses for women and 14 for men were categorized as heavy alcohol consumption. Binge drinking was assessed with the question: "How often do you drink enough alcohol to feel yourself drunk?" with 4 response options. The answers reflecting drinking at least once a week were categorized as "regular binge drinking" for analyses. Length of sleep was captured with an open-ended question" How many hours do you usually sleep during one night"? The following questions concerned memory, learning and concentration and were followed by the answering options very well; well; adequately; poorly; very poorly. "How well does your memory work?", "How easily do you learn new information and new things to do?" and "How well can you concentrate on things?" Current use of medications was assessed as follows: "Have you used any of the following types of medicines over the past 7 days?" (Sedatives; sleeping pills; anti-depressants) followed by yes/no alternatives.

Current stress factors were assessed only in the post-intervention questionnaire. Work-related distress was captured by asking "How often do you find yourself annoyed that you have to push yourself to the limit in order to cope with your present job or workload?" with 5 response options. "Offspring-related distress was asked as follows "Have your children caused you particular problems?" with 6 response options.

Four items measured adherence. The following sentences were followed by a 7-point Likert scale; "I performed the exercises as instructed"; "The instructions of the exercises were clear"; the exercise program was useful" (Appendix 1). The question "Would you recommend these exercises to others?" was followed by the response options Yes; No; and cannot say (Appendix 2).

\section{Drop out}

Drop out was analyzed using logistic regression, where missingness in the final inquiry was explained by different covariates. These included age, gender, school years, living arrangements, medication (antidepressants, sleeping medication, tranquilizers), smoking, physical exercise, BDI score and happiness score. To test whether the effect of the covariate on missingness was different in the treatment groups, covariate-treatment group interactions were also included in the models. After examining all covariates in separate models, a joint model was estimated where all significant $(\mathrm{p}<0.1)$ predictors and interaction terms were included in the same model in order to detect all independent effects of the covariates.

Participant flow through the study from recruitment to data analysis is summarized (Figure 1)

\section{Statistical analyses}

The HFS was validated in a separate sample representing the Finnish population aged 17-79, which was contacted in March and recontacted in November of $2009(\mathrm{~N}=2035, \mathrm{RR}=41 \%)$. The construct validity was studied estimating convergence with two known life satisfaction scales, the Satisfaction With Life Scale (SWLS)[32] and Life Satisfaction (LS) [33]. The standardized (0-100) population mean of the HFS was 69 points (men 68 points and women 70 points). The reliability coefficient Cronbach's alpha was .93. The convergence correlations of the summed scales were .81 (SWLS) and .76 [LS].

The means and standard deviations were reported as the descriptive statistics in addition to the group sizes and number of observations in different treatment groups and measurements points. The statistical analyses were based on the intention-to-treat principle and linear random effects models [34]. Random effects models allow the regression coefficients to vary randomly from one individual to the other accounting for the similarity among repeated observations of the same subject. These models also account for missing data assuming missing-at-random. In the primary analysis the fixed effects of the model contained the main effects of treatment groups and the followup time as categorical covariates, and their interaction.

The individual random effects part of the model contained the intercept and slope thus allowing individual linear trends, disregarding the physical exercise groups, which only included the random intercept. The nonequivalence of the three treatments was tested using the Wald test on the interaction terms. Gender-time interaction was also tested to determine possible differences of treatment effects between men and women.

BDI score was logarithmized for normality. Physical exercise was analyzed by random effects logistic regression using a dichotomised outcome, which divided the sample into physically active and nonactive participants (active=heavy exercise at least $3 \mathrm{~h}$ per week or regular competitive exercise, non-active=no exercise or light exercise at least $4 \mathrm{~h}$ per week). Sample characteristics associating with both the outcome variables and the intervention group were studied in order to define possible confounding factors. Age was the only background variable found to be associated with the intervention group and therefore was included in the analysis as a confounding factor. 
Citation: Joutsenniemi K, Kaattari C,Pankakoski M, Langinvainio H, Lönnqvist J Mattila AS, et al. (2014) E-mail-based Exercises in Happiness, Physical Activity and Readings: A Randomized Trial on 3274 Finns. J Psychiatry 17: 1000140. doi:10.4172/2378-5756.1000140

Page 5 of 13

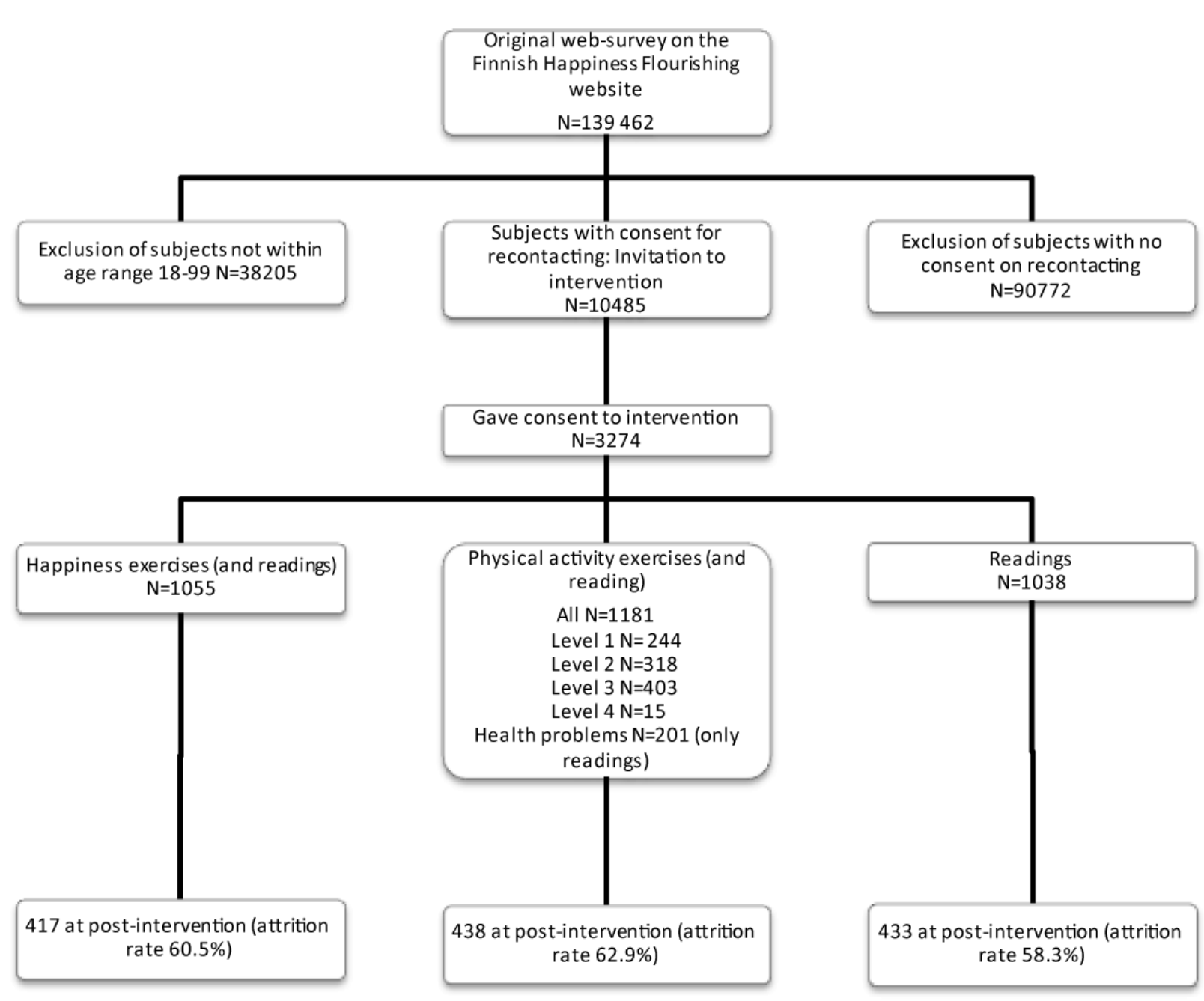

Figure 1: Flow chart

In the secondary analyses the nonequivalence of the happiness exercise permutations inthe happiness group was tested. That is, we tested whether changes in the happiness scores depended on the order, in which the four different happiness exercises were administered. Men and women were analyzed jointly. A random effects model which contained the permutation group as a categorical covariate and followup time as main effects and their interaction as fixed effects was applied. The random effects part was the same as in the model of the primary analysis. As the number of permutations, 24, was relatively large when compared to the number of participants in the happiness group, another model, into which four binary indicator (dummy) variables corresponding to the four happiness exercises and having values 0 or 1 were entered, and in which the outcome variable was defined as the change in the original outcome variable values during a measurement interval, was applied. The random effects part of the model contained only the intercept. Because the mini-inquiries contained only a subset of the outcome measures or subjects did not participate to some mini-inquiries, there were $1,2,3$ or 4 exercises during a measurement interval, thus at least one and at most four of the dummy variables had value 1 for the measurement interval, respectively. For example, if a subject participated in every measurement point and was assigned to the optimism exercise between baseline and the first mini inquiry, the dummy variable corresponding to the optimism exercise had value 1 and all other dummy variables corresponding to the other exercises had value 0 for that measurement interval. If a subject answered only the baseline and the post intervention questionnaires, he or she did all the exercises between the two measurements and hence during that interval all of the dummy variables had value 1 . Because the order of the happiness exercises was randomized, the order of the happiness exercises was ignored thus allowing a comparison of the effects of the different happiness exercises.

\section{Results}

\section{Characteristics of the data}

There were 420 men (13\%) and 2731 women (83\%), and $123(4 \%)$ subjects who did not indicate their gender in the final sample (Table $1)$. In the age range $18-78$, the mean age was about 42 years. The 
Citation: Joutsenniemi K, Kaattari C,Pankakoski M, Langinvainio H, Lönnqvist J Mattila AS, et al. (2014) E-mail-based Exercises in Happiness, Physical Activity and Readings: A Randomized Trial on 3274 Finns. J Psychiatry 17: 1000140. doi:10.4172/2378-5756.1000140

Page 6 of 13

participants had completed 16,5 (sd 3,2) years of school on average. About on third lived alone, one third lived with their spouse, and one third lived with their spouse and children, whereas about $10 \%$ were single parents.About $11 \%$ were current smokers. While training for sports competitions was rare, less than one third exercised very little, one third engaged in light physical activity at least 4 hours a week, and over one third performed heavy exercise at least 3 hours per week. About $14 \%$ used antidepressants, whereas use of sleep medications or tranquilizers was less common.

\begin{tabular}{|c|c|c|c|c|c|c|}
\hline & & $\begin{array}{l}\text { Place control } \\
\text { group } \mathrm{N}=1038\end{array}$ & $\begin{array}{l}\begin{array}{l}\text { Physical } \\
\text { groupN=1181 }\end{array} \\
\text { exercise }\end{array}$ & $\begin{array}{ll}\text { p } & \text { (Physical } \\
\text { exercise } & \text { vs } \\
\text { placebo) }\end{array}$ & $\begin{array}{l}\text { Happiness } \\
\text { group } N=1055\end{array}$ & $\begin{array}{l}p_{\text {placebo) }} \quad \text { (Happiness vs } \\
\text { vs }\end{array}$ \\
\hline \multicolumn{7}{|l|}{$\mathrm{Age}^{\mathrm{a}}$} \\
\hline mean $(\mathrm{sd})$ & & $41.86(12.25)$ & $42.9(11.83)$ & 0.04 & $42.85(12.15)$ & 0.07 \\
\hline \multicolumn{7}{|l|}{ Gender $^{b}$} \\
\hline \multirow[t]{3}{*}{$N(\%)$} & Male & $142(14)$ & $150(13)$ & 0.54 & $128(13)$ & 0.39 \\
\hline & Female & $862(86)$ & $992(87)$ & & $877(87)$ & \\
\hline & Missing & 34 & 39 & & 50 & \\
\hline \multicolumn{7}{|c|}{ Education years ${ }^{a}$} \\
\hline mean $(\mathrm{sd})$ & & $16.58(3)$ & $16.37(3.2)$ & 0.09 & $16.49(3.3)$ & 0.52 \\
\hline \multicolumn{7}{|c|}{ Current main activity ${ }^{b}$} \\
\hline \multirow[t]{7}{*}{$N(\%)$} & $\begin{array}{l}\text { Full-time } \\
\text { employment }\end{array}$ & $620(60)$ & 748 (63) & 0.72 & 619 (59) & 0.55 \\
\hline & $\begin{array}{l}\text { Part-time } \\
\text { employment }\end{array}$ & $82(8)$ & $90(8)$ & & $82(8)$ & \\
\hline & Student & $102(10)$ & $97(8)$ & & $83(8)$ & \\
\hline & Retired & $92(9)$ & $98(8)$ & & $112(11)$ & \\
\hline & $\begin{array}{l}\text { Unemployed or laid } \\
\text { off }\end{array}$ & $51(5)$ & $51(4)$ & & $61(6)$ & \\
\hline & $\begin{array}{l}\text { Management of } \\
\text { own household or } \\
\text { care of family } \\
\text { members }\end{array}$ & $42(4)$ & $44(4)$ & & $47(4)$ & \\
\hline & Other & $49(5)$ & $53(4)$ & & $51(5)$ & \\
\hline \multicolumn{7}{|c|}{$\begin{array}{l}\text { Work capacity } \\
\text { Do you think that, as far as } \\
\text { your health is concerned, } \\
\text { you could continue in your } \\
\text { present occupation after } \\
\text { two years? }\end{array}$} \\
\hline \multirow[t]{4}{*}{$N(\%)$} & Probably not & $59(6)$ & $50(4)$ & 0.23 & $61(6)$ & 0.51 \\
\hline & I am not sure & $91(9)$ & $96(8)$ & & $108(10)$ & \\
\hline & Probably yes & $865(85)$ & $1008(87)$ & & $863(84)$ & \\
\hline & Missing & 23 & 27 & & 23 & \\
\hline \multicolumn{7}{|c|}{ Living arrangements $^{b}$} \\
\hline \multirow[t]{3}{*}{$N(\%)$} & Alone & $291(28)$ & $298(25)$ & 0.50 & $285(27)$ & 0.51 \\
\hline & With spouse & $320(31)$ & $357(30)$ & & $330(31)$ & \\
\hline & $\begin{array}{l}\text { With spouse and } \\
\text { children }\end{array}$ & $297(29)$ & 378 (32) & & $315(30)$ & \\
\hline
\end{tabular}


Citation: Joutsenniemi K, Kaattari C,Pankakoski M, Langinvainio H, Lönnqvist J Mattila AS, et al. (2014) E-mail-based Exercises in Happiness, Physical Activity and Readings: A Randomized Trial on 3274 Finns. J Psychiatry 17: 1000140. doi:10.4172/2378-5756.1000140

Page 7 of 13

\begin{tabular}{|c|c|c|c|c|c|c|}
\hline & $\begin{array}{l}\text { With children (single } \\
\text { parent/joint custody) }\end{array}$ & $86(8)$ & $102(9)$ & & $96(9)$ & \\
\hline & $\begin{array}{l}\text { With a parent/ } \\
\text { parents }\end{array}$ & $11(1)$ & $14(1)$ & & $8(1)$ & \\
\hline & Other & $33(3)$ & $32(3)$ & & $21(2)$ & \\
\hline \multicolumn{7}{|c|}{$\begin{array}{l}\text { Relationship satisfaction } \\
(-3 ;-3)^{a}\end{array}$} \\
\hline mean (sd) & & $1.45(1.53)$ & $1.53(1.45)$ & 0.15 & $1.46(1.5)$ & 0.83 \\
\hline \multicolumn{7}{|c|}{ Smoking daily ${ }^{\mathrm{b}}$} \\
\hline \multirow[t]{2}{*}{$N(\%)$} & No & $928(89)$ & $1046(89)$ & 0.58 & $939(89)$ & 0.82 \\
\hline & Yes & $110(11)$ & $135(11)$ & & $116(11)$ & \\
\hline \multicolumn{7}{|c|}{$\begin{array}{l}\text { Heavy } \\
\text { consumption }{ }^{b c} \quad \text { alcohol }\end{array}$} \\
\hline \multirow[t]{3}{*}{$N(\%)$} & No & $142(14)$ & $154(13)$ & 0.56 & $134(13)$ & 0.60 \\
\hline & Yes & $870(86)$ & $1023(87)$ & & $886(87)$ & \\
\hline & Missing & 26 & 4 & & 35 & \\
\hline \multicolumn{7}{|c|}{ Binge drinking ${ }^{b}$} \\
\hline \multirow[t]{5}{*}{$\mathrm{N}(\%)$} & $\begin{array}{l}\text { At least } 2 \text { times a } \\
\text { week }\end{array}$ & $28(3)$ & $33(3)$ & 0.29 & $30(3)$ & 0.89 \\
\hline & $\begin{array}{l}\text { At least once a } \\
\text { week }\end{array}$ & $88(9)$ & $117(10)$ & & $84(8)$ & \\
\hline & $\begin{array}{l}\text { At least once a } \\
\text { month }\end{array}$ & $258(25)$ & $256(22)$ & & $249(24)$ & \\
\hline & $\begin{array}{l}\text { Less than once a } \\
\text { month }\end{array}$ & $660(64)$ & $765(65)$ & & $683(65)$ & \\
\hline & Missing & 4 & 10 & & 9 & \\
\hline \multicolumn{7}{|c|}{ Length of sleep ${ }^{a}$} \\
\hline mean (sd) & & $7.43(1.03)$ & $7.4(0.98)$ & 0.44 & $7.42(0.97)$ & 0.75 \\
\hline \multicolumn{7}{|l|}{ Memory ${ }^{b}$} \\
\hline \multirow[t]{5}{*}{$\mathrm{N}(\%)$} & Very good & $171(16)$ & $182(15)$ & 0.5 & $155(15)$ & 0.17 \\
\hline & Good & $559(54)$ & $662(56)$ & & $589(56)$ & \\
\hline & Adequate & $254(24)$ & $287(24)$ & & $273(26)$ & \\
\hline & Poor & $51(5)$ & $44(4)$ & & $33(3)$ & \\
\hline & Very poor & $3(0)$ & $6(1)$ & & $5(0)$ & \\
\hline \multicolumn{7}{|l|}{ Learning $^{b}$} \\
\hline \multirow[t]{5}{*}{$\mathrm{N}(\%)$} & Very good & $209(20)$ & $211(18)$ & 0.1 & 199 (19) & 0.77 \\
\hline & Good & $542(52)$ & $686(58)$ & & $564(53)$ & \\
\hline & Adequate & $255(25)$ & $253(21)$ & & $256(24)$ & \\
\hline & Poor & $28(3)$ & $28(2)$ & & $34(3)$ & \\
\hline & Very poor & $4(0)$ & $3(0)$ & & $2(0)$ & \\
\hline
\end{tabular}


Citation: Joutsenniemi K, Kaattari C,Pankakoski M, Langinvainio H, Lönnqvist J Mattila AS, et al. (2014) E-mail-based Exercises in Happiness, Physical Activity and Readings: A Randomized Trial on 3274 Finns. J Psychiatry 17: 1000140. doi:10.4172/2378-5756.1000140

Page 8 of 13

\begin{tabular}{|c|c|c|c|c|c|c|}
\hline \multicolumn{7}{|c|}{ Concentration $^{b}$} \\
\hline \multirow[t]{5}{*}{$\mathrm{N}(\%)$} & Very good & $156(15)$ & $186(16)$ & 0.21 & $178(17)$ & 0.36 \\
\hline & Good & $512(49)$ & $617(52)$ & & $525(50)$ & \\
\hline & Adequate & $304(29)$ & $318(27)$ & & $304(29)$ & \\
\hline & Poor & $58(6)$ & $57(5)$ & & $42(4)$ & \\
\hline & Very poor & $8(1)$ & $3(0)$ & & $6(1)$ & \\
\hline \multicolumn{7}{|c|}{ Anti-depressants ${ }^{b}$} \\
\hline \multirow[t]{2}{*}{$N(\%)$} & No & $887(85)$ & $1031(87)$ & 0.23 & $911(86)$ & 0.60 \\
\hline & Yes & $151(15)$ & $150(13)$ & & $144(14)$ & \\
\hline \multicolumn{7}{|c|}{ Sleeping pills ${ }^{b}$} \\
\hline \multirow[t]{2}{*}{$N(\%)$} & No & $951(92)$ & $1069(91)$ & 0.41 & $957(91)$ & 0.51 \\
\hline & Yes & $87(8)$ & $112(9)$ & & $98(9)$ & \\
\hline \multicolumn{7}{|l|}{ Sedatives $^{b}$} \\
\hline \multirow[t]{2}{*}{$N(\%)$} & No & $1000(96)$ & $1144(97)$ & 0.60 & $1012(96)$ & 0.70 \\
\hline & Yes & $38(4)$ & $37(3)$ & & $43(4)$ & \\
\hline \multicolumn{7}{|c|}{$\begin{array}{l}\text { Offspring-related distress } \\
(1-6)^{\text {a d }}\end{array}$} \\
\hline mean $(\mathrm{sd})$ & & $3.41(2.05)$ & $3.63(2.01)$ & 0.12 & $3.63(2.01)$ & 0.12 \\
\hline \multicolumn{7}{|c|}{$\begin{array}{l}\text { Work-related distress (1-5) } \\
\text { a d }\end{array}$} \\
\hline mean $(s d)$ & & $2.56(1.06)$ & $2.48(1.04)$ & 0.29 & $2.45(1.01)$ & 0.11 \\
\hline \multicolumn{7}{|c|}{ Happiness score $(0-100)^{a}$} \\
\hline mean $(s d)$ & & $71.45(18.82)$ & $72.88(18.12)$ & 0.07 & $71.91(18.77)$ & 0.57 \\
\hline \multicolumn{7}{|l|}{ BDI suma } \\
\hline mean $(\mathrm{sd})$ & & $8.67(7.58)$ & $8.13(6.78)$ & 0.08 & $8.47(7.47)$ & 0.54 \\
\hline \multicolumn{7}{|c|}{ Physical exercise ${ }^{b}$} \\
\hline \multirow[t]{5}{*}{$\mathrm{N}(\%)$} & Not much exercise & $267(26)$ & $320(27)$ & 0.92 & $298(28)$ & 0.53 \\
\hline & $\begin{array}{l}\text { At least } 4 \mathrm{~h} \text { light } \\
\text { exercise per week }\end{array}$ & $355(34)$ & $397(34)$ & & $361(34)$ & \\
\hline & $\begin{array}{l}\text { At least } 3 \mathrm{~h} \text { heavy } \\
\text { exercise per week }\end{array}$ & $396(38)$ & $444(38)$ & & $375(36)$ & \\
\hline & $\begin{array}{l}\text { Training for sports } \\
\text { competitions }\end{array}$ & $16(2)$ & $18(2)$ & & $16(2)$ & \\
\hline & Missing & 4 & 2 & & 5 & \\
\hline
\end{tabular}

a T-test used, ${ }^{\mathrm{b}}$ Chi square test used, ${ }^{\mathrm{c}}$ At least 7 weekly doses for women and 14 for men was categorized as heavy alcohol consumption, ${ }^{\mathrm{d}}$ Data taken from post-intervention. Table 1: Sample characteristics in different treatment groups. Baseline data on 3274 Finns

\section{Drop out}

Altogether 1617 participants answered the first mini-inquiry, while the second was completed by 855 participants, 281 in the Happiness group, 282 in the physical exercise group and 292 in the placebocontrol group. The final attendance and attrition was similar in all groups. Of the 3274 who registered, 1288 completed the final inquiry, 417 of which were in the Happiness group (attrition rate 60.5\%), 438 were in the physical exercise group (attrition rate 62.9\%) and 433 were in the placebo-control group (attrition rate 58.3\%). The total attrition rate was approximately $60.7 \%$. 
Citation: Joutsenniemi K, Kaattari C,Pankakoski M, Langinvainio H, Lönnqvist J Mattila AS, et al. (2014) E-mail-based Exercises in Happiness, Physical Activity and Readings: A Randomized Trial on 3274 Finns. J Psychiatry 17: 1000140. doi:10.4172/2378-5756.1000140

Page 9 of 13

Age was a significant predictor of missingness in the final inquiry suggesting that younger participants were more likely to drop out from the study $(\mathrm{p}<0.001)$. There was a significant interaction between antidepressants and treatment group: Antidepressant users especially in the physical exercise group were more likely to drop out from the study compared to antidepressant users in the placebo group $(\mathrm{p}=0.05)$. An interaction between gender and treatment group was at borderline significance $(\mathrm{p}=0.09)$ indicating that men in the happiness group were more likely to drop out compared to men in the placebo group. Baseline values of the happiness scores, BDI or physical exercise did not associate with drop out in this sample.
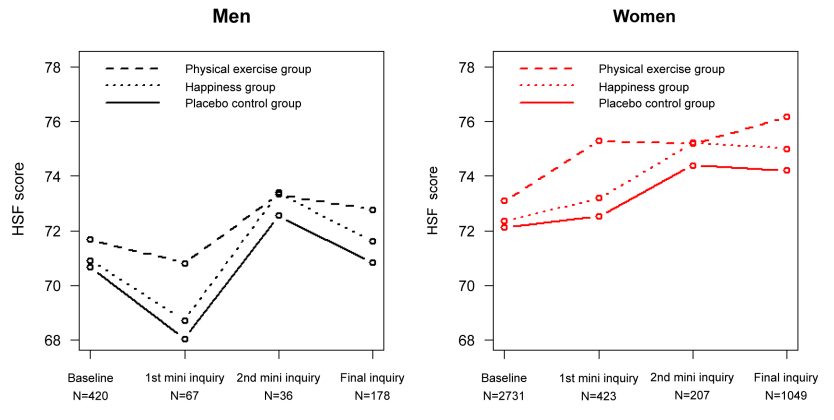

Figure 2: Changes in happiness score among men and women. Total change in the score was significant $(\mathrm{p}=0.05)$. Gender-time interaction was significant $(\mathrm{p}=0.03)$. Group-time interaction was not significant $(\mathrm{p}=0.55)$. Baseline to $1^{\text {st }}$ mini inquiry: 8 weeks; $1^{\text {st }}$ mini inquiry to $2^{\text {nd }}$ mini inquiry: 4 weeks; $2^{\text {nd }}$ mini inquiry to Final inquiry: 8 weeks.

\begin{tabular}{|l|l|l|l|l|l|l|l|l|}
\hline & \multicolumn{2}{|l|}{$\begin{array}{l}\text { Placebo } \\
\text { (reading) } \\
\text { group }\end{array}$} & \multicolumn{2}{l|l|l|l|l|}{$\begin{array}{l}\text { Physical } \\
\text { exercise } \\
\text { groups }\end{array}$} & \multicolumn{2}{l|}{$\begin{array}{l}\text { Happiness } \\
\text { group a }\end{array}$} & \multicolumn{2}{|l|}{ Total } \\
\cline { 2 - 9 } & $\mathrm{N}$ & $\%$ & $\mathrm{~N}$ & $\%$ & $\mathrm{~N}$ & $\%$ & $\mathrm{~N}$ & $\%$ \\
\hline Yes & 262 & 60.65 & 286 & 66.05 & 292 & 70.36 & 840 & 65.62 \\
\hline No & 39 & 9.03 & 24 & 5.54 & 24 & 5.78 & 87 & 6.8 \\
\hline $\begin{array}{l}\text { Undecide } \\
\text { d }\end{array}$ & 131 & 30.32 & 123 & 28.41 & 99 & 23.86 & 353 & 27.58 \\
\hline
\end{tabular}

Appendix 1: Would you recommend these exercises to others?

\section{Happiness}

The happiness score (HFS) was measured at four different time points, which were the baseline, the first mini inquiry, the second mini inquiry and the final inquiry. The happiness score increased significantly in the whole sample during the intervention $\left(\mathrm{X}^{2}=7.8\right.$, $\mathrm{df}=3, \mathrm{p}=0.05$ Figure 2). The change in the happiness score was different between men and women, indicated by the significant gender-time interaction $\left(\mathrm{X}^{2}=9.0, \mathrm{df}=3, \mathrm{p}=0.03\right)$. Women continued to increase their happiness score throughout the study whereas for men the change was not linear and the increase between the first and the final inquiry was small. Sample sizes were comparatively small for men in the mini inquiries, resulting to less accurate estimation. There were no significant differences among either gender in the changes between the different intervention groups indicated by the non-significant group-time interaction $\left(\mathrm{X}^{2}=5.0, \mathrm{df}=6, \mathrm{p}=0.55\right)$.

\begin{tabular}{|l|l|l|l|l|}
\hline & $\begin{array}{l}\text { Placebo } \\
\text { group }\end{array}$ & $\begin{array}{l}\text { Physical } \\
\text { exercise } \\
\text { groups }\end{array}$ & $\begin{array}{l}\text { Happiness } \\
\text { group }\end{array}$ & Total \\
\hline $\begin{array}{l}\text { The exercise } \\
\text { program was } \\
\text { useful }\end{array}$ & $0.93(1.5)$ & $0.56(1.69) \mathrm{a}$ & $1.01(1.53) \mathrm{b}$ & $0.83(1.59)$ \\
\hline $\begin{array}{l}\text { I performed the } \\
\text { exercises as } \\
\text { instructed }\end{array}$ & $-0.36(1.91)$ & $0.4(1.74) \mathrm{b}$ & $0.01(1.87)$ \\
\hline $\begin{array}{l}\text { The instructions } \\
\text { of the exercises } \\
\text { were clear }\end{array}$ & & $1.54(1.41)$ & $1.59(1.56)$ & $1.56(1.49)$ \\
\hline
\end{tabular}

Appendix 2 : (mean (sd), scale: $[-3 ; 3])$

\section{Order and efficacy of happiness exercises}

Secondary analysis for the happiness group alone (data not shown) revealed that the order of the four different happiness exercises did not have a systematic effect on the happiness score. The main effect of the permutation group was not significant nor its interaction with the follow-up time $\left(\mathrm{X}^{2}=27, \mathrm{df}=23, \mathrm{p}=0.25\right.$ and $\mathrm{X}^{2}=19, \mathrm{df}=23, \mathrm{p}=0.73$, respectively). However, when comparing the effects of the different happiness exercises on the change in the original outcome variable during a measurement interval, some differences were observed. The overall effect of the type of the happiness exercise was significant (likelihood ratio test $=10.21, p=0.04$ ). The good deeds exercise appeared to have the strongest effect on the improvement of the happiness score (change in the happiness score $=4.50,95 \%$ $\mathrm{CI}=2.47-6.52$ ) whereas for the optimism exercise there was no improvement (change $=0.46,95 \% \mathrm{CI}=-1.55-2.48$ ).
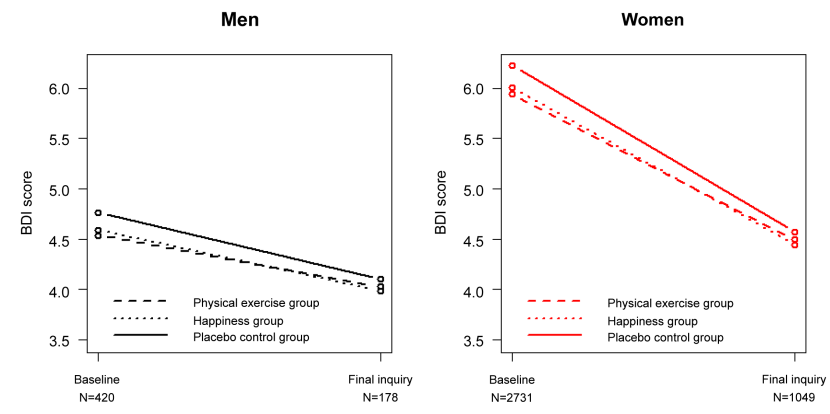

Figure 3: Changes in physical activity (i.e. Leave out the addition "among men and women").

\section{Depressive symptoms}

The BDI score decreased significantly in the whole sample during the intervention $\left(\mathrm{X}^{2}=5.5, \mathrm{df}=1, \mathrm{p}=0.02\right.$, Figure 3$)$. The decline was more pronounced among women than men (interaction term $\mathrm{X}^{2}=7.3$, $\mathrm{df}=1, \mathrm{p}=0.007$ ). The changes did not differ significantly between the intervention groups $\left(\mathrm{X}^{2}=0.4, \mathrm{df}=2, \mathrm{p}=0.83\right)$. In subanalysis of low and 
Citation: Joutsenniemi K, Kaattari C,Pankakoski M, Langinvainio H, Lönnqvist J Mattila AS, et al. (2014) E-mail-based Exercises in Happiness, Physical Activity and Readings: A Randomized Trial on 3274 Finns. J Psychiatry 17: 1000140. doi:10.4172/2378-5756.1000140

Page 10 of 13

high BDI points at baseline, there were few differences in the decrease of BDI points between the intervention groups (data not shown).

\section{Physical activity}

The proportion of physically active subjects in the whole sample decreased during the intervention according to the random effects logistic regression analysis $(\mathrm{X} 2=5.4, \mathrm{df}=1, \mathrm{p}=0.02$ (Figure 4$)$. However, in the physical exercise group there was an increase in the proportion of physically active subjects [placebo vs. physical exercise grp $\times$ time interaction: $\mathrm{X} 2=8.4, \mathrm{df}=1, \mathrm{p}=0.004$. No significant gender differences were observed in the change of physical activity in time.

\begin{tabular}{|l|l|l|l|l|l|}
\hline & $\begin{array}{l}\text { Physical } \\
\text { condition, } \\
\text { only } \\
\text { reading } \\
\text { exercises }\end{array}$ & $\begin{array}{l}\text { Not } \\
\text { much } \\
\text { exercis } \\
\text { e }\end{array}$ & $\begin{array}{l}\text { At least } \\
\text { 4h light } \\
\text { exercise } \\
\text { per week }\end{array}$ & $\begin{array}{l}\text { At least 3h } \\
\text { heavy } \\
\text { exercise } \\
\text { per week }\end{array}$ & $\begin{array}{l}\text { Training } \\
\text { for sports } \\
\text { competitio } \\
\text { ns }\end{array}$ \\
\hline Baseline (N) & 201 & 244 & 318 & 403 & 15 \\
\hline $\begin{array}{l}\text { Post- } \\
\text { intervention } \\
\text { (N) }\end{array}$ & 89 & 79 & 108 & 150 & 6 \\
\hline $\begin{array}{l}\text { Attrition rate } \\
\text { (\%) }\end{array}$ & 55.7 & 67.6 & 66.0 & 62.8 & 60.0 \\
\hline
\end{tabular}

Appendix 3: Attrition rate in different physical exercise groups.

\section{Adherence}

Over $60 \%$ of participants in all intervention groups would recommend the program to others (Appendix 1), and the $70 \%$ of recommenders in the happiness exercise intervention group differed significantly from the placebo group. The happiness exercise group was more likely than the physical exercise group to find the intervention useful, whereas the happiness group did not differ from the placebo group. The happiness group was more likely than the physical exercise group to perform the exercises as instructed. The groups did not differ on how clear they considered the instructions.

\section{Discussion}

\section{Main results}

A major public health challenge is to increase the awareness and availability of interventions for mental health promotion. This study on 3274 Finns examined the effectiveness of email-based happiness and physical activity exercises compared with placebo emails containing reading material. To the best of our knowledge, previous web-based happiness interventions have not compared physical exercise interventions with happiness exercises. Furthermore, information on relevance if the order of happiness exercises is lacking. The results support the first and second hypothesis as overall happiness scores increased and depressive symptoms decreased from pre- to post-intervention in the happiness exercise and physical exercise groups. In contrast to our third hypothesis, also the placebo group demonstrated an increase in happiness scores and a decrease in depressive symptoms. In line with our fourth hypothesis, the order of the four different happiness exercises did not have a systematic effect on the happiness score. In contrast to our fifth hypothesis, the exercise on good deeds had the strongest effect on the improvement of the happiness score, whereas the optimism exercise appeared to have no effect on happiness. Finally, as hypothesised, there was an increase in physical activity in the physical exercise group, but not in the other groups.

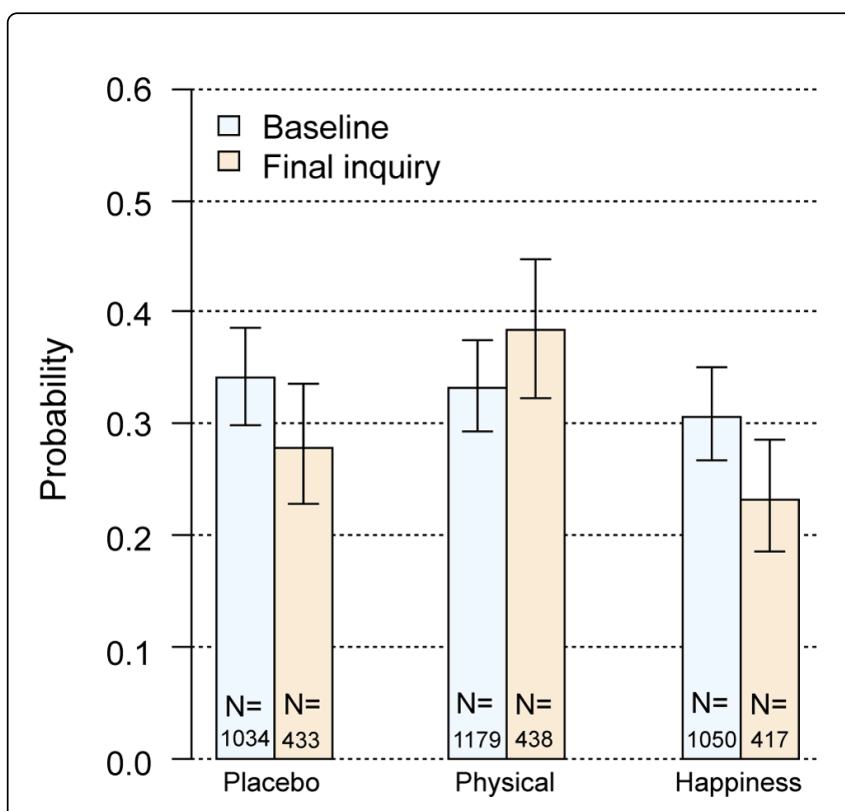

Figure 4: Changes in physical activity among men and women. Total change in physical activity was significant $(\mathrm{p}=0.02)$. Grouptime interaction for physical exercise group vs. placebo group was significant $(\mathrm{p}=0.004)$. Baseline to Final inquiry 20 weeks $/ 5$ months.

\section{Comparison with previous studies}

Consistent with previous research $[2,6,13,14]$, women were overrepresented and the sample was relatively well-educated. We found women to increase their happiness score throughout the study, whereas for men the change was not linear and the total increase in happiness was small. Previous online intervention studies with a majority of women have also reported increases in happiness $[2,13,14]$. Disregarding one study [2] that found no gender differences in happiness, the previous studies did not assessed gender differences $[13,14]$. The study on mainly male subjects [35] reported no improvement on happiness symptoms. Further studies are needed in order to determine ways to promote happiness among men.

We found that the order of the four different happiness exercises, i.e. optimism, good deeds, gratitude and reducing rumination, did not have a systematic effect on the happiness score. To the best of our knowledge, no previous studies have reported results on the order of exercises. The exercise on good deeds appeared to have the strongest effect on the improvement of the happiness score. We suggest that the advantage of the good deeds exercise may be concrete action instead of pure mental work, as well as potential interaction with the social environment, which is known to have happiness enhancing effects. Optimism appeared to have no effect, whereas other exercises had some effect on happiness scores. Shapira et al. [14] reported positive changes with the optimism exercise, whereas Abbott and colleagues [35] found no effect with a multi-component program including optimism. In our study, the optimism exercise on writing about life 
goals for 15 minutes may have been too vague or repetitive. In line with our study, Seligman et al. found [2] the gratitude exercise effective in increasing happiness. As the length of follow-up varied between 1 week and 4 months due to the drop-out of the individuals, any comparisons between studies must be cautious. Furthermore, we used a new measure of happiness, i.e. the HFS. Our measure is based on an integrated well-being model and is thus similar to measures used in two previous studies [2,14].

There is consistent evidence on the benefit of physical activity in alleviating depressive symptoms [15], but less previous evidence on physical activity having beneficial effects happiness. However, one must bear in mind that all intervention groups received placebo readings on happiness, which may have alleviated the differences between the intervention groups and increased the happiness of subjects in the physical activity and placebo groups. Furthermore, the mere attention produced by receiving emails from a virtual happiness coach and any subsequent act performed, be it reading, or doing happiness or physical exercises, may enhance one's happiness during an intervention.

The level of depressive symptoms decreased significantly in the whole sample during the intervention. The mean baseline BDI score of about 8.1-8.7 was only slightly higher than the score reported in the population-based Finnish Health 2000 Study (women mean 8.02; men mean 6.25) [36] suggesting that the level of depressive symptoms was within the normal range. Two previous studies with relatively healthy samples reported no changes in depressive symptoms [13,35] whereas decreases have been reported in samples with higher baseline depressive symptoms $[2,14]$.

The physical exercise intervention proved to increase the proportion of physically active men and women at post-intervention. As data on the effectiveness of a web-based program on reducing sedentary behaviour in primary care patients has been lacking [18], our study provides promising short-term results.

\section{Methodological issues}

There are several strengths in this study. First, the sample size was considerably larger than in previous online positive psychology interventions, which enabled better detection of differences between several intervention groups, i.e. and active physical exercise groups and a less active reading group. Second, our cross-over design enabled examining the relevance of the order of separate happiness exercises. Third, the frequent assessments of the happiness measure provided a comprehensive picture of the development of happiness during the intervention. Fourth, we were able to assess a wide range of confounding factors, although the possibility of residual confounding cannot be fully excluded. Fifth, regarding areas of improvement for future interventions, we provide data on how participants performed the recommended exercises and whether they found the programs useful.

The intention-to-treat (ITT) analyses are used for estimating effectiveness, which represent the average effect of the treatment when used widely in practice. This means that also the possible noncompliance is similar both in the clinical trial and in practice. Another question would be the estimation of efficacy, which is the "true biological effect" of the treatment. Estimation of efficacy would require adjustment for non-compliance and much more complicated analytical methods in addition the compliance information, and this was not our objective, but would be an interesting and important topic of future work.

However, there are also limitations in this study that must be considered. First, although this is one of the largest online positive psychologies intervention studies so far, the sample size was still relatively small, which may have hindered the observation of some differences. The benefits of the different interventions on men would probably have been clearer with more data. Second, this study does not represent the entire population. As only $10.4 \%(\mathrm{~N}=10485)$ had given approval for recontacting the generalizability of the results is quite limited. In particular, we were unable to rigorously assess the male population. Third, the original TV-program on happiness may have attracted a distressed, particularly motivated sample looking to increase their happiness. Thus, participating in a "happiness-study" may have increased their happiness as such. A previous sample on selfhelp seeking adults reported depressive symptoms above the mean of the general population and accordingly, life satisfaction below the average [6]. In analysis of the originally collected web-based data, based on which selected subjects were recruited to the intervention about 12 months later, the happiness scores of the contacted sample had increased on average by about 4 points among women, and by about 3 points among men (Table 2).

\begin{tabular}{|c|c|c|c|c|}
\hline & All & $\begin{array}{l}\text { Placebo } \\
\text { control group }\end{array}$ & $\begin{array}{l}\text { Physical } \\
\text { exercise } \\
\text { group }\end{array}$ & $\begin{array}{l}\text { Happiness } \\
\text { group }\end{array}$ \\
\hline & mean (sd) $\mathrm{N}$ & mean (sd) $\mathrm{N}$ & mean (sd) $\mathrm{N}$ & mean (sd) $\mathrm{N}$ \\
\hline $\begin{array}{l}\text { Before } \\
\text { baseline }\end{array}$ & $\begin{array}{l}67.39 \\
\mathrm{~N}=1190\end{array}$ & $\begin{array}{l}67.01 \\
\mathrm{~N}=404\end{array}$ & $\begin{array}{l}67.53 \\
N=410\end{array}$ & $\begin{array}{l}67.63 \\
N=376\end{array}$ \\
\hline Baseline & $\begin{array}{l}71.73 \\
\mathrm{~N}=1190\end{array}$ & $\begin{array}{l}71.36 \\
N=404\end{array}$ & $\begin{array}{l}71.49 \\
N=410\end{array}$ & $\begin{array}{l}72.39 \\
\mathrm{~N}=376\end{array}$ \\
\hline $\begin{array}{l}\text { Mini-enquiry } \\
1\end{array}$ & $\begin{array}{l}71.99 \\
N=325\end{array}$ & $\begin{array}{l}70.39 \\
N=119\end{array}$ & $\begin{array}{l}71.94 \\
\mathrm{~N}=95\end{array}$ & $\begin{array}{l}73.77 \\
N=111\end{array}$ \\
\hline $\begin{array}{l}\text { Mini-enquiry } \\
2\end{array}$ & $\begin{array}{l}74.72 \\
\mathrm{~N}=196\end{array}$ & $\begin{array}{l}72.85 \\
\mathrm{~N}=75\end{array}$ & $\begin{array}{l}74.92 \\
\mathrm{~N}=51\end{array}$ & $\begin{array}{l}76.58 \\
N=70\end{array}$ \\
\hline $\begin{array}{l}\text { Post- } \\
\text { intervention }\end{array}$ & $\begin{array}{l}74.27 \\
\mathrm{~N}=1190\end{array}$ & $\begin{array}{l}73.29 \\
N=404\end{array}$ & $\begin{array}{l}74.6 \\
N=410\end{array}$ & $\begin{array}{l}74.94 \\
N=376\end{array}$ \\
\hline
\end{tabular}

Table 2: Changes in happiness scores [HFS] in the whole sample and among different intervention groups from before baseline to postintervention

With caution, this may reflect spontaneous improvement in general well-being before the start of the intervention. Furthermore, as described previously, the BDI score at pre-intervention was only marginally higher than the national average. Fourth, the happiness intervention was not tailored according to the subject's needs. Higher tailoring of happiness exercises may lead to better results, as suggested by the promising results in our tailored physical activity program. Fifth, the study limitations included a common problem in web- based intervention studies, i.e. high study attrition (60.7\%) at postintervention. However, the participants who dropped out of the study did not differ from those who remained on their baseline happiness or depression scores. We tested various background factors for their association with drop-out from the follow-up. Age was found to be a significant predictor of drop-out, but without interaction with the intervention group, thus the selection mechanism due to age was likely to operate in the same way in all groups. It is likely that age did not 
create bias in the estimated differences of the intervention groups. Only one interaction of antidepressants and treatment group was found significant (gender and treatment group was at borderline significance) suggesting that the drop-out was selective, thus the estimated differences of the intervention groups could be biased. The random-effects model which we applied is able to handle the effects of missing data assuming that it is missing-at-random, but more detailed analyses based on, for example, multiple imputation would be an important topic of future research. Finally, we only have subjective, self-reported data on health status and other background variables. Furthermore, several areas, such as physical activity, were only measured only by one item.

Although we need new tools for tackling high attrition, online delivery of health enhancing exercises has the potential to reach large audiences, even if some population subgroups commit to only to the first steps of the intervention.

\section{Conclusions}

This study produced further evidence on the effectiveness of webbased happiness exercises and on the relative importance of the order of exercises in a pre-designed program. More research is, however, still needed to assess the potentially negative effects of valuing happiness too strongly [37]. Further studies also need to increase the current understanding of the relative importance of variety in the application of positive interventions [38]. All in all, online positive psychology interventions can become a powerful tool in helping reduce well-being disparities, particularly among populations with little access to other services.

\section{References}

1. Seligman ME, Csikszentmihalyi M (2000) Positive psychology. An introduction. Am Psychol 55: 5-14.

2. Seligman ME, Steen TA, Park N, Peterson C (2005) Positive psychology progress: empirical validation of interventions. Psychol 60: 410-421.

3. Sin NL, Lyubomirsky S (2009) Enhancing well-being and alleviating depressive symptoms with positive psychology interventions: a practicefriendly meta-analysis. J Clin Psychol 65: 467-487.

4. Atkinson NL, Saperstein SL, Pleis J (2009) Using the internet for healthrelated activities: findings from a national probability sample. J Med Internet Res 11: e4.

5. Ritterband LM, Thorndike FP, Cox DJ, Kovatchev BP, Gonder-Frederick LA (2009) A behavior change model for internet interventions. Ann Behav Med 38: 18-27.

6. Parks AC, Della Porta MD, Pierce RS, Zilca R, Lyubomirsky S (2012) Pursuing happiness in everyday life: the characteristics and behaviors of online happiness seekers. Emotion 12: 1222-1234.

7. Cuijpers P, van Straten A, Smit F, Mihalopoulos C, Beekman A (2008) Preventing the onset of depressive disorders: a meta-analytic review of psychological interventions. Am J Psychiatry 165: 1272-1280.

8. Beddington J, Cooper CL, Field J, Goswami U, Huppert FA, et al. (2008) The mental wealth of nations. Nature 455: 1057-1060.

9. Mitchell J, Vella-Brodrick D, Klein B (2010) Positive psychology and the internet: A mental health opportunity. Electronic Journal of Applied Psychology 6: 30-41.

10. Andrews G, Cuijpers P, Craske MG, McEvoy P, Titov N (2010) Computer therapy for the anxiety and depressive disorders is effective, acceptable and practical health care: a meta-analysis. PLoS One 5: e13196.

11. Morgan AJ, Jorm AF, Mackinnon AJ (2012) Email-based promotion of self-help for subthreshold depression: Mood Memos randomised controlled trial. Br J Psychiatry 200: 412-418.
12. Powell J, Hamborg T, Stallard N, Burls A, McSorley J, et al. (2012) Effectiveness of a web-based cognitive-behavioral tool to improve mental well-being in the general population: randomized controlled trial. J Med Internet Res 15: e2.

13. Mitchell J, Staminirovic R, Klein B, Vella-Brodrick D (2009) A randomised controlled trial of a self-guided internet intervention promoting well-being. Computers in Human Behavior 25: 749-760.

14. Shapira L, Mongrain M (2010) The benefits of self-compassion and optimism exercises for individuals vulnerable to depression. Journal of Positive Psychology 5: 377-389.

15. Rimer J, Dwan K, Lawlor D, Greig C, McMurdo M, et al. (2012) Exercise for depression. Cochrane Database Syst Rev;Jul 117: CD004366.

16. Kuoppala J, Lamminpää A, Husman P (2008) Work health promotion, job well-being, and sickness absences--a systematic review and metaanalysis. J Occup Environ Med 50: 1216-1227.

17. Rosenbaum S, Sherrington C (2011) Is exercise effective in promoting mental well-being in older age? A systematic review. Br J Sports Med 45: 1079-1080.

18. Marcus BH, Ciccolo JT, Sciamanna CN (2009) Using electronic/ computer interventions to promote physical activity. Br J Sports Med 43: 102-105.

19. Joutsenniemi K, Härkänen T, Pankakoski M, Langinvainio H, Mattila A, et al. (2013) Confidence in the future, health-related behaviour and psychological distress: results from a web-based cross-sectional study of 101257 Finns BMJ Open;electronic publication 13 June.

20. Mattila A, Aarninsalo P (2009) Onnentaidot (in Finnish). Keuruu: Duodecim Medical Publications Ltd.

21. Lyubomirsky S, Sheldon K, Schkade D (2005) Pursuing happiness: The architecture of sustainable change. Review of general psychology 9: $111-31$.

22. Lyubomirsky S (2007) The how of happiness. New York: Penguin press.

23. Emmons RA, McCullough ME (2003) Counting blessings versus burdens: an experimental investigation of gratitude and subjective wellbeing in daily life.J Pers Soc Psychol 84: 377-389.

24. King L (2001). The health benefits of writing about life goals. Personality and Social Psychology Bulletin 27: 798-807.

25. Dolan Y (1998). One small step. Moving beyond trauma and therapy to a life of joy. Watsonville, CA: Papier-Mache Press.

26. Canadian Society for Exercise Physiology (1994). PAR-Q and You. Gloucester, Ontario, Canada: 1-2.

27. Raitasalo R (1977) Depressio ja sen yhteys psykoterapian tarpeeseen. (in Finnish). Helsinki Kansaneläkelaitoksen julkaisuja A: 13.

28. Lightfoot SL, Oliver JM (1985) The Beck Inventory: psychometric properties in university students.J Pers Assess 49: 434-436.

29. Nuevo R, Dunn G, Dowrick C, Vázquez-Barquero JL, Casey P, et al. (2009) Cross-cultural equivalence of the Beck Depression Inventory: a five-country analysis from the ODIN study.J Affect Disord 114: 156-162.

30. Beck AT, Ward CH, Mendelson M, Mock J, Erbaugh J (1961) An inventory for measuring depression. Arch Gen Psychiatry;4:561-71.

31. Wilhelmsen L, Tibblin G, Werkö L (1972) A primary preventive study of Gothenburg, Sweden.Prev Med 1: 153-160.

32. Diener E, Emmons RA, Larsen RJ, Griffin S (1985) The Satisfaction With Life Scale.J Pers Assess 49: 71-75.

33. Allardt E (1973) About Dimension of Welfare: An Explanatory Analysis of the Comparative Scandinavian Survey. Helsinki: University of Helsinki.

34. Laird NM, Ware JH (1982) Random-effects models for longitudinal data.Biometrics 38: 963-974.

35. Abbott J, Klein B, Hamilton C, Rosenthal A (2009) The impact of online resilience training for sales managers on wellbeing and work performance. Electronic Journal of Applied Psychology 5: 89-95.

36. Elovainio M, Aalto AM, Kivimäki M, Pirkola S, Sundvall J, et al. (2009) Depression and C-reactive protein: population-based Health 2000 Study.Psychosom Med 71: 423-430. 
Citation: Joutsenniemi K, Kaattari C,Pankakoski M, Langinvainio H, Lönnqvist J Mattila AS, et al. (2014) E-mail-based Exercises in Happiness, Physical Activity and Readings: A Randomized Trial on 3274 Finns. J Psychiatry 17: 1000140. doi:10.4172/2378-5756.1000140

Page 13 of 13

37. Mauss IB, Tamir M, Anderson CL, Savino NS (2011) Can seeking happiness make people unhappy? (corrected) Paradoxical effects of valuing happiness.Emotion 11: 807-815.

38. Sheldon K, Boehm J, Lyubomirsky S. Variety is the spice of happiness: The hedonic adaptation prevention (HAP) model. In Boniwell I, David S editors. Oxford handbook of happiness. Oxford: Oxford University Press; in press. 